RESEARCH ARTICLE

\title{
Functional heterogeneity of metabolites excreted by fungal and bacterial biofilms and their effects on seedling growth
}

\author{
I.D. Singhalage ${ }^{1,3^{*}}$, G. Seneviratne ${ }^{1}$ and H.M.S.P. Madawala ${ }^{2}$ \\ ${ }^{1}$ Microbial Biotechnology Unit, National Institute of Fundamental Studies, Kandy, Sri Lanka \\ ${ }^{2}$ Department of Botany, Faculty of Science, University of Peradeniya, Peradeniya, Sri Lanka \\ ${ }^{3}$ Department of Science and Technology, Faculty of Applied Sciences, Uva Wellassa University of Sri Lanka, Badulla, \\ Sri Lanka
}

Received: 23/07/2019; Accepted: 23/01/2020

\begin{abstract}
Environmental conditions and physical interactions between microbial cells may alter the metabolites released by them. The present study examined the functional differences of metabolites excreted by three biofilms viz., a fungal biofilm of Aspergillus sp. (FB), a bacterial biofilm of Enterobactor sp. (BB), and their mixed-culture biofilm (FBB). All three biofilms were formed under in vitro conditions and their cell-free exudates were analyzed for functional properties using Fourier Transform Infrared (FTIR) spectroscopy. Further, a germination assay was carried out using lettuce seeds. Functional molecules produced by the FBB have clustered separately from the rest showing the distinctiveness of molecules produced by FBB. All three biofilms showed a higher accumulation of functional molecules during their mature stages than that in the early stages of their development. The lettuce seeds treated with FBB exudates showed a noteworthy growth increment in comparison to FB and $\mathrm{BB}$ treated seedlings. The highest seedling vigor was shown by lettuce seeds treated with 0.5 day old FBB exudates, while the least was demonstrated in seeds treated with 6 day old BB, FB and FBB exudates. The results suggest that the accumulation of functional molecules seems to incur phytotoxic effects on lettuce seedlings. In conclusion, 0.5 day old FBB exudates can be used to promote the growth of lettuce seedlings. The study emphasizes the importance of selecting specific biofilms over microbes at species level in developing biofertilizers.
\end{abstract}

Keywords: biofilms, exudates, functionality.

\section{INTRODUCTION}

Functional properties of microbes have many applications in food, medicine and agriculture-related industries. Microbial functionality or metabolome is the collection of all metabolites and it shifts in response to environmental changes. The total functionality of a cell reflects its activities at a particular time (Garcia et al., 2008), thus deciding phenotypical responses under different environmental circumstances (Sardans et al., 2011). It is also a powerful tool to monitor the phenotypic variability of genotypic responses to environmental changes (Sardans et al., 2011). A biofilm is a biotic interaction between individuals of the same microbial species or else between two or many species. The biofilm formation can be induced by the cell density of a particular microorganism and stressful environmental conditions they are exposed to. Metabolic activities of biofilms are different to that of cells in their planktonic mode, as the horizontal gene transfer among individuals can cause alterations to their genetic makeup (Madsen et al., 2012). The individuals in biofilms are known to show superior functional properties in comparison to their monoculture counterparts. Zavahir and Seneviratne (2007) showed the presence of a higher number of monosaccharide compounds in a Penecillium sp.-Bradyrhizobium elkanii SEMIA 5019 biofilm in comparison to its monocultures. Herath et al. (2013) also showed a unique pattern of biochemical expression in a FBB developed from Colletotrichum and Azotobacter in comparison to their respective monocultures. Scientists over the years have shown many benefits of FBBs in agriculture. For example, Seneviratne and Jayasinghearachchi (2005) showed an increased $\mathrm{N}$ and $\mathrm{P}$ mineralization in soil and a higher nitrogenase activity in Bradyrhizobium japonicum SEMIA5019 - Penicillium biofilm compared to its monocultures. Biofilms have also demonstrated a higher acidity and concentration of indole acetic acid-like substances in comparison to their respective mono-cultures (Bandara et al., 2006). According to another study, a biofilm between Xanthoparmelia mexicana and Bradyrhizobium elkanii SEMIA 5019 released a higher concentration of phosphorus from Eppawala rock phosphate than that of other microbial treatments (Seneviratne and Indrasena, 2006). Singhalage et al. (2019) showed the potential of using an Aspergillus sp.-Enterobactor sp. biofilm as a biofertilizer to produce strawberry in a more profitable manner. Thus, the present study characterized the functionality of metabolites excreted by fungal and bacterial biofilms using seedling growth. The monocultures of Aspergillus sp. (FB) and Enterobactor sp. (BB) and their mixed-cultures (FBB) were used as test biofilms. 


\section{MATERIALS AND METHODS}

An Aspergillus sp. and an Enterobactor sp. isolated from the rhizosphere of cultivated strawberry (Fragaria x ananassa) were used in the study. Using them, a fungal biofilm (FB), a bacterial biofilm (BB) and a fungal-bacterial biofilm (FBB) were produced in culture flasks containing $100 \mathrm{~mL}$ of Biofilm Forming Medium (BFM). The medium without microbes was used as the control (Cont). Three replicates of culture flasks containing the three biofilms and the control were incubated under room temperature $\left(25^{\circ} \mathrm{C}\right)$ for six days in a shaker $(80 \mathrm{rpm})$. Morphological characteristics of the biofilms were observed under a light microscope after mounting the cultures with lacto phenol cotton blue stain. From each flask, $20 \mathrm{~mL}$ of the BFM were collected at 0.25 , $0.5,1.5,3$ and 6 days following inoculation. Samples were centrifuged (6000 rpm for 20 min; SANYO Harrier 18/80) and the supernatant was filtered by syringe filtration $(20$ $\mu \mathrm{m})$. The filtrate $(1.0 \mathrm{~mL})$ was concentrated by vacuum drying (Eyela, VOS-4500) under $50{ }^{\circ} \mathrm{C}$ until it reached the final volume of $\sim 50 \mu \mathrm{L}$. The absorbance spectra of concentrated exudates were measured at the range of 650 $4,000 \mathrm{~cm}^{-1}$ with a resolution of $4 \mathrm{~cm}^{-1}$ by Fourier Transform Infrared (FTIR, Thermo Nicolet, USA) spectroscopy. Each spectrum was produced by using 256 scans. During the spectral analysis, baseline of each spectrum was corrected by automatic base line correction function. Peaks of functional groups were visualized in amides $(1,500-1,800$ $\left.\mathrm{cm}^{-1}\right)$, fatty acids $\left(1,400-1,500 \mathrm{~cm}^{-1}\right.$ and $2,800-3,000 \mathrm{~cm}^{-}$ $\left.{ }^{1}\right)$ and polysaccharides $\left(900-1,200 \mathrm{~cm}^{-1}\right)$ windows. Spectra were collected and analyzed by OMINIC $\AA$ software. The peak absorbance values under different biofilms were analyzed using ANOVA. Treatment means were separated by Tukey's simultaneous mean separation test. Functional similarity of different biofilm exudates in each spectral window was analyzed by Hierarchical Cluster Analysis (HCA).

The filtrate (devoid of concentration) was used in the lettuce seed germination assay as follows. Lettuce seeds were surface sterilized by soaking seeds in a commercial clorox solution $(1 \% \mathrm{w} / \mathrm{v})$ for 5 minutes and then the seeds were washed and drained repeatedly using sterile distilled water (Abdul-Baki, 1974). Twenty five lettuce seeds were soaked in biofilm exudates for 2 hours before they were placed on wet paper towels in sterile disposable petri plates. The petri plates were kept under dark conditions for 48 hours to initiate germination. After 5 days, the number of germinating seeds was counted in each treatment, and the length of each seedling was measured. The results were expressed as germination percentage and seedling vigor index (SVI) where SVI $=$ Mean length of seedling $\times$ Percentage germination (Haque et al., 2007).

Functional properties of biofilms were correlated with the germination percentages of lettuce seeds and the vigor of lettuce seedling by Pearson correlation. Statistical tests were performed using Minitab ${ }^{\circledR}$ 16.2.1, 2010.

\section{RESULTS AND DISCUSSION}

Polysaccharide concentration was significantly higher $(\mathrm{p}<$ 0.05 ) in all biofilm exudates over the control on the $3^{\text {rd }}$ day following inoculation (Figure 1a). The amide concentration was significantly higher $(\mathrm{p}<0.05)$ in FBB in comparison to the control at 0.25 day. In contrast, FBB showed significantly low $(\mathrm{p}>0.05)$ amide concentrations on $3^{\text {rd }}$ and $5^{\text {th }}$ days in comparison to the BB and the control. Functional fatty acids were significantly the highest $(p<0.05)$ in BB exudates collected from 3-day old biofilms (Figure 1c). In the 0.5 day old biofilms, FB secreted a significantly higher polysaccharide level than the FBB (Figure 1a), while the amides also showed similar results (Figure 1b). The fatty acids showed no significant differences between the treatments (Figure 1c). The controls (only BFM without biofilms) also showed the presence of polysaccharides, amides and fatty acids as they contained different types of carbohydrates and some other macromolecules. Though functional properties of FBB were not significantly different, they were unique compared to the other two types of biofilms, as was proved from the cluster analysis of biofilm metabolites. Considering all spectral windows such as polysaccharide, amide and fatty acids, the FBB produced a distinct group of chemical compounds in comparison to the two mono-specific biofilms studied (i.e. BB and FB) (Figure 2). Herath et al. (2013) also showed a unique pattern of biochemical expression in FBBs developed from Colletotrichum and Azotobacter in comparison to their monospecific counterparts. The polysaccharide-based functional groups that were recorded in the control, $\mathrm{BB}$ and $\mathrm{FB}$ showed $\approx 99 \%$ similarity in all harvest times (Figure 2a). Functionality of 0.25 days old FBB showed $\approx 90 \%$ similarity to the functionality of the other two biofilms at all times (Figure 2a). Mature FBB showed approximately $80 \%$ similarity to the functional groups produced by the other two biofilms at $0.5,1.5,3$ and 6 days (Figure 2a). Hierarchical Cluster Analysis (HCA) of amides and fatty acids also showed clustering patterns similar to polysaccharides (Figures $2 \mathrm{~b}$ and $2 \mathrm{c}$ ).

These variations of metabolites are attributed to the fact that the metabolome of biofilms generally changes with the maturation of biofilms (Wong et al., 2018, Singhalage et al., 2018). Polysaccharides (Jiao et al., 2010), amides (O’Toole and Kolter, 1998) and fatty acids are major components of Extracellular Polymeric Substances (EPS) of biofilms, which provide a strong and sticky framework to protect biofilms against adverse environmental conditions (Sutherland, 2001). The multidimensional structure of EPS biopolymers (Flemming et al., 2007) could provide space to trap many functional biomolecules that are released from biofilms indicating a direct contribution of EPS to the functionality of biofilm exudates. It is also known that amides or proteins help microbial cells to attach to the substratum during the initial stages of biofilm formation (Crouzet et al., 2014), thus the continued protein synthesis is not required during the latter stages of biofilm (O'Toole and Kolter, 1998). In agreement with that, the concentration of amide-based functional groups in our study decreased by the $6^{\text {th }}$ day in all three biofilms (Figure 1b). Furthermore, microbial interactions regulate genes that encode proteins with unknown functions, thus these regulatory genes seem to play an important role in adapting microorganisms to their environment (Deveau et al., 2015), thus inducing 
biofilm formation under stressful conditions.

Microorganisms excrete fatty acids as they pseudosolubilize hydrocarbons thus facilitating C uptake (Mapelli et al., 2008). Soberón-Chávez et al. (2005) showed a synthesis of glycolipid surface-active molecules by a rhizospheric plant growth promoting bacterial strain, Pseudomonas aeruginosa. Present study also showed that the amount of biomolecules released by the biofilms was related to their maturity stages (Figure 1), thus indicating a relationship of the metabolome to the growth phase. Allen et al. (2003) also showed substantial variations of microbial exometabolome throughout different growth phases of microbes.

The metabolic heterogeneity among microorganisms
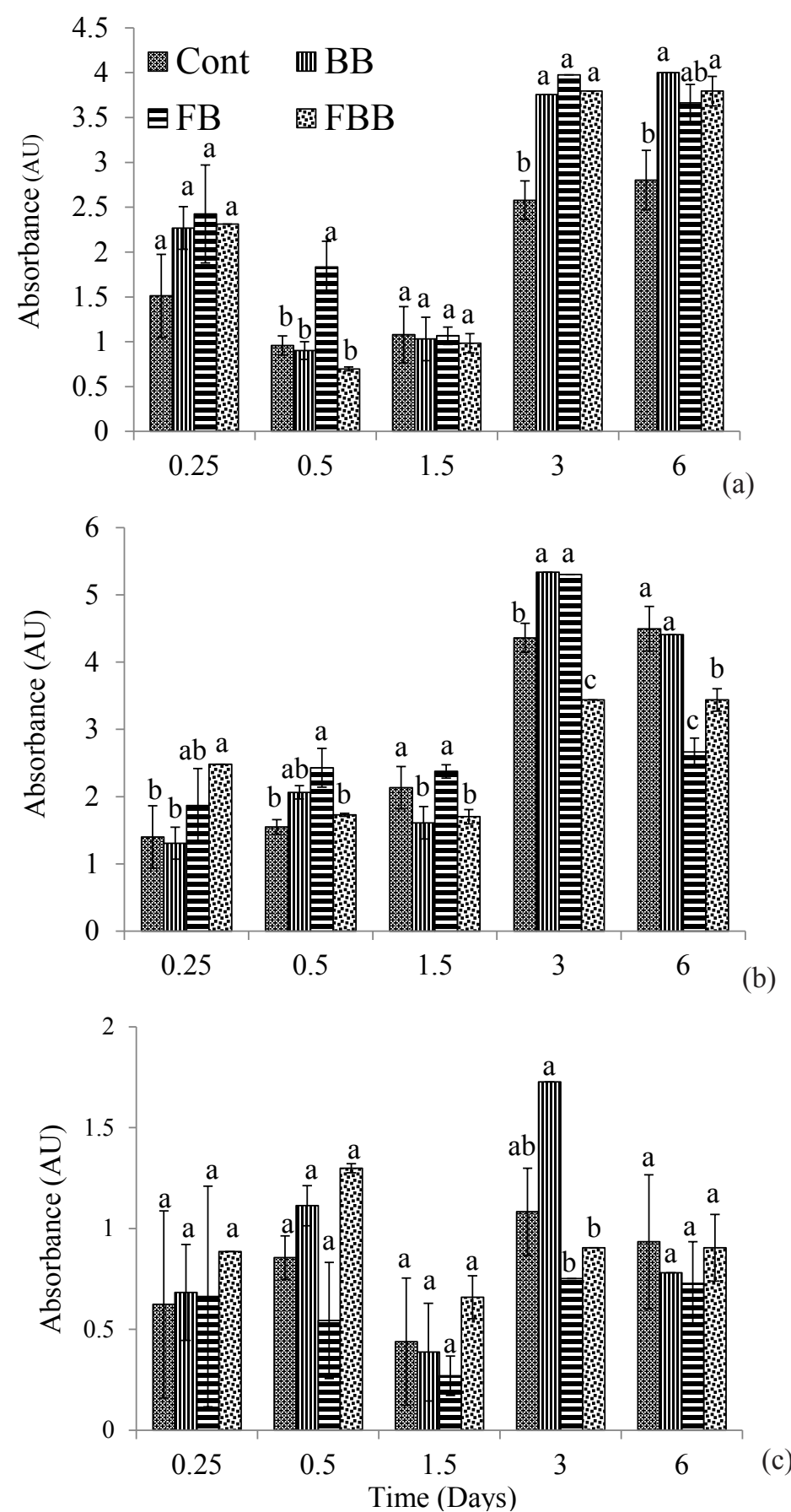

Figure 1: Differences of concentrations of functional polysaccharides (a), amides (b) and fatty acids (c) of biofilms in four maturity stages 0.5, 1.5, 3 and 6 days. BB - Bacterial biofilm, FB - Fungal biofilm, FBB - Fungal-bacterial biofilm. Data were gathered from polysaccharide $\left(900-1,200 \mathrm{~cm}^{-1}\right)$, amide $\left(1,500-1,800 \mathrm{~cm}^{-1}\right)$ and fatty acids $\left(2,800-3,000 \mathrm{~cm}^{-1}\right.$ and $\left.1,400-1,500 \mathrm{~cm}^{-1}\right)$ windows of FTIR spectrum. Columns headed by the same letter in the same harvest are not significantly different at $5 \%$ probability level. AU absorbance units. 


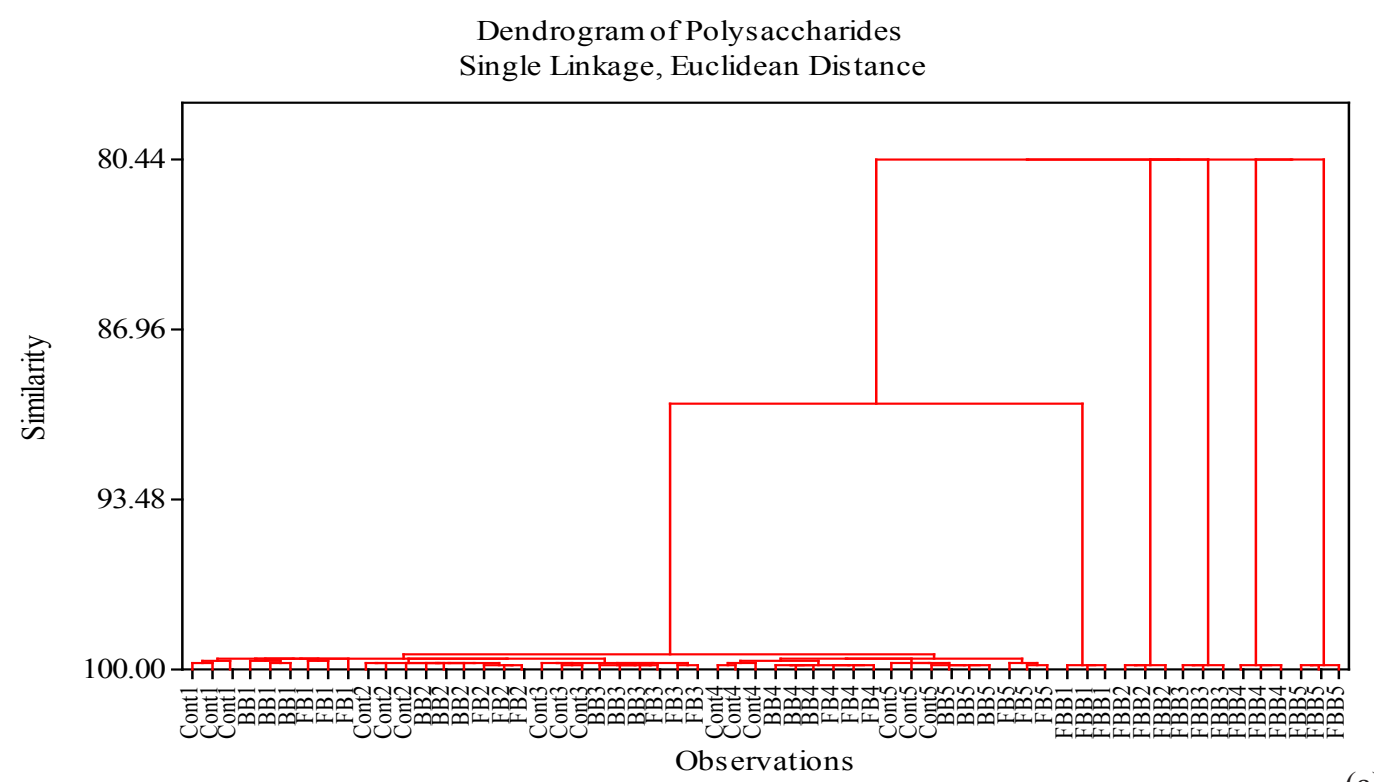

Dendrogram of Fatty acids

(a)

Single Linkage, Euclidean Distance

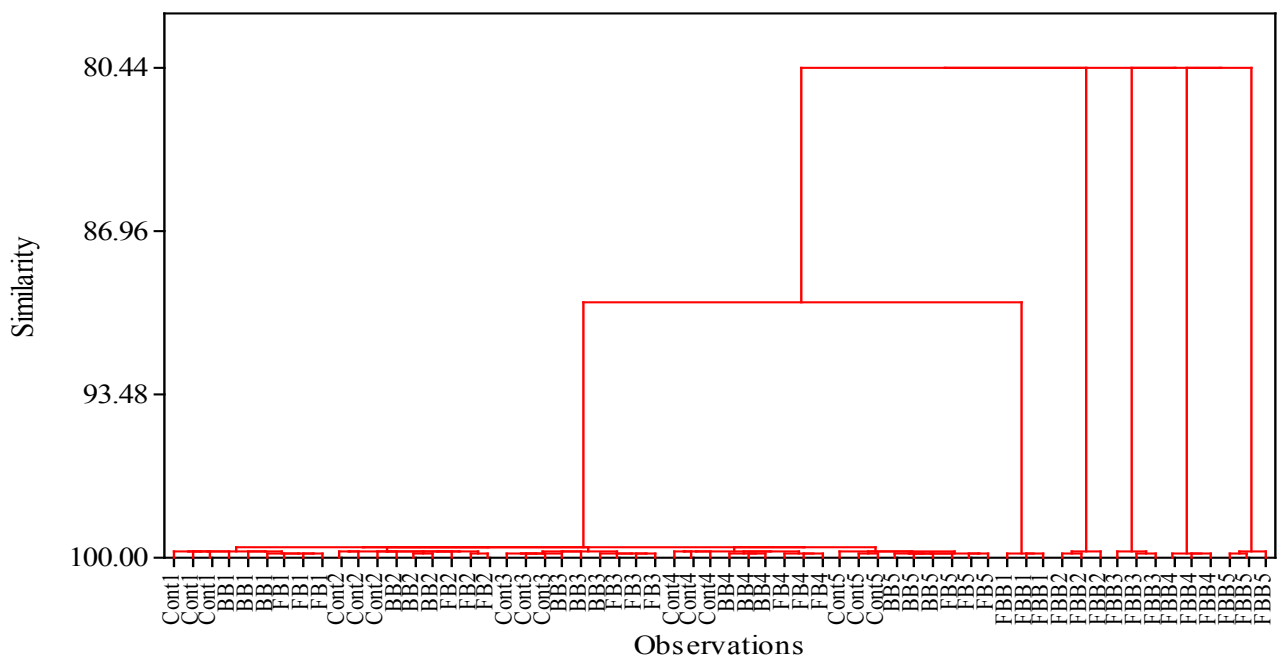

(b)

Dendrogram of Amides

Single Linkage, Euclidean Distance

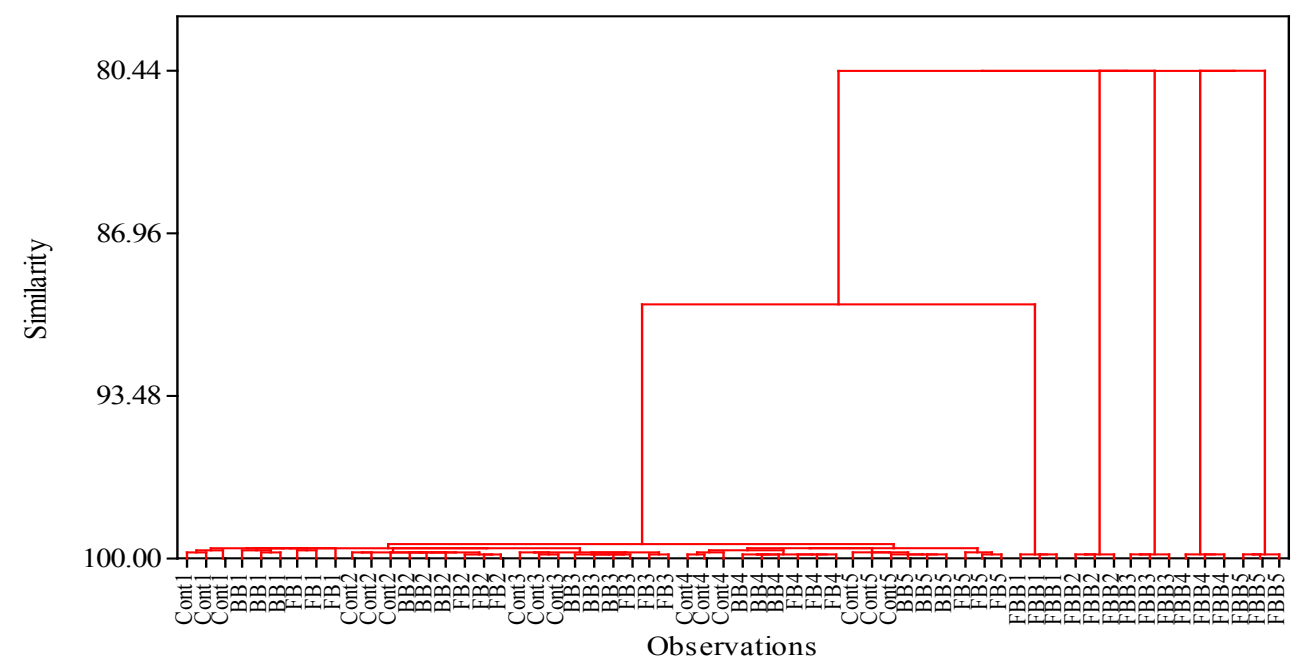

(c)

Figure 2 : Dendrogram showing hierarchical cluster analysis of FTIR spectral functional groups of, (a) polysaccharide (900 - 1200 cm-1), (b) fatty acid (2800 - $3000 \mathrm{~cm}-1$ and $\left.1400-1500 \mathrm{~cm}^{-1}\right)$ and (c) amide (1500 - $\left.1800 \mathrm{~cm}-1\right)$ exudates of bacterial (BB), fungal (FB) and fungal - bacterial (FBB) biofilms at five $(0.25,0.5,1.5,3$ and 6 days) harvests. Number followed by each treatment and control represent the harvesting times $(1=0.25,2=0.5,3=1.5,4=3$ and $5=6$ days $)$. 
was observed when they were in intimate physical interactions with other microorganisms, especially with individuals from a different domain. In FBBs, fungal filaments act as the substratum for the bacterial cells to get colonized (Figure 3). Detachment and re-attachment of bacterial cells to fungal filaments were observed during the formation of the FBB. The genetic manipulation occurring in FBB produces more diverse functional groups than that of monoculture-based biofilms (Molin and TolkerNielsen, 2003). BB expressed the EPS accumulation by enlarging cells over time. In addition, planktonic bacterial cells got aggregated together in liquid medium by acting the bacterial cell surface as a substratum for the formation of BB. In fungal biofilm formation, the density and slimy nature of the fungal filaments increased with the formation and maturation of the biofilm. Similarly, Singhalage et al. (2018) also explained the morphological and structural properties of fungal, bacterial and fungal-bacterial biofilms when they were changing from planktonic form to the biofilm mode. The biofilmed microorganisms contain more diverse genomic potential than their planktonic modes largely due to the transfer of genetic materials (Jefferson, 2004). This unique feature enables them to produce distinct functional compounds. Schroeckh et al. (2009) showed an activation of a specific gene in Aspergillus when it forms an interaction with a bacterial strain. An intimate physical interaction between the bacterial and fungal strains is mandatory to elicit specific responses (Schroeckh et al., 2009). Deveau et al. (2015) too showed specific metabolic responses of Laccaria bicolor $\mathrm{S} 238 \mathrm{~N}$ when it was in a fungalbacterial interaction possibly as a result of exchanging metabolites or competing for nutrients, which remains still to be investigated. The physical interactions and signaling molecules help microorganisms to communicate with each other, thus activating silent biosynthetic genes (Schroeckh et al., 2009) while improving the metabolic activity.

Microbial exudates have shown the potential to promote plant growth. According to the lettuce seed germination assay in the present study, the highest seedling

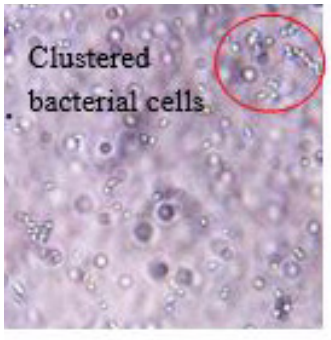

Bacterial biofilm

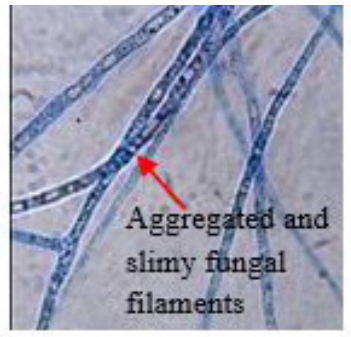

Fungal biofilm

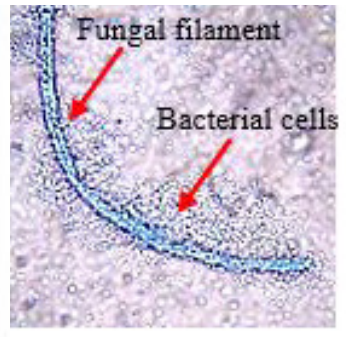

Fungal-bacterial biofilm

Figure 3: Morphological differences of three types of biofilms - fungal (FB), bacterial (BB) and fungal-bacterial (FBB). Magnification x 1000 .

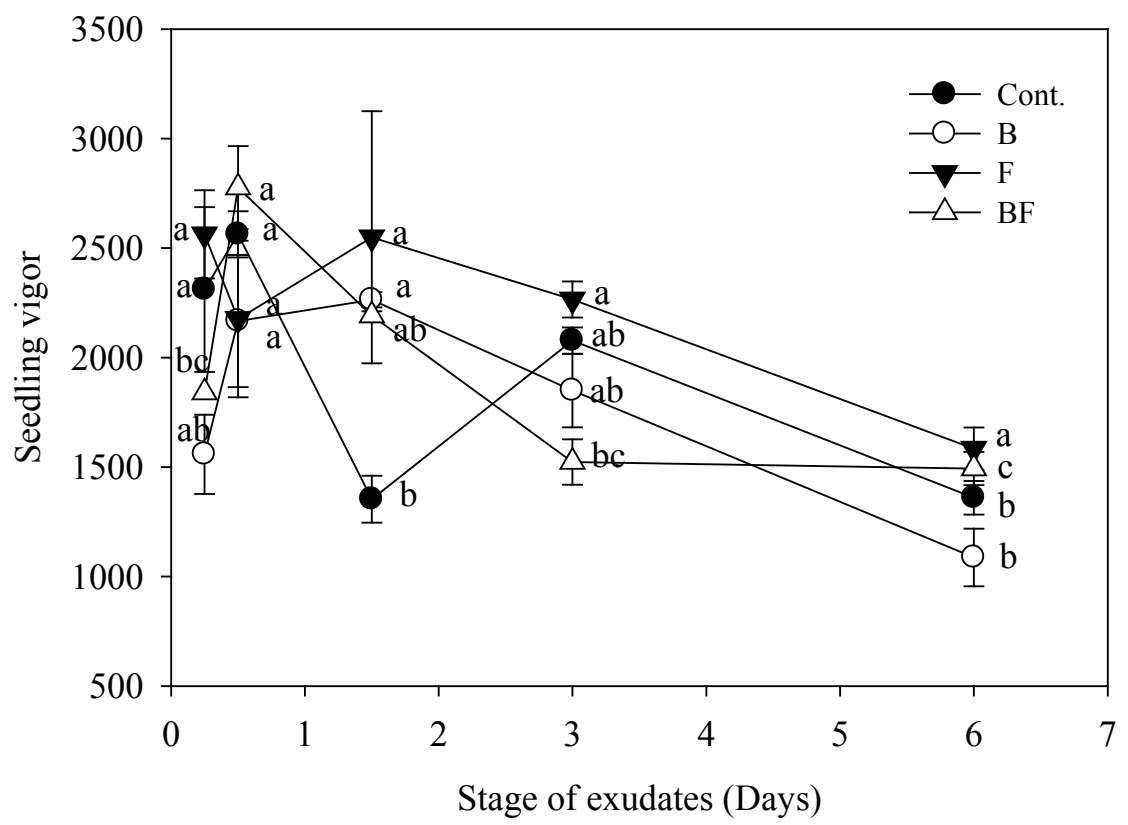

Figure 4: Change in lettuce seedling vigor with the application of biofilm exudates harvested at different time intervals. Maximum vigor was shown by seedlings treated from 0.5 days old fungal-bacterial biofilm exudates. 


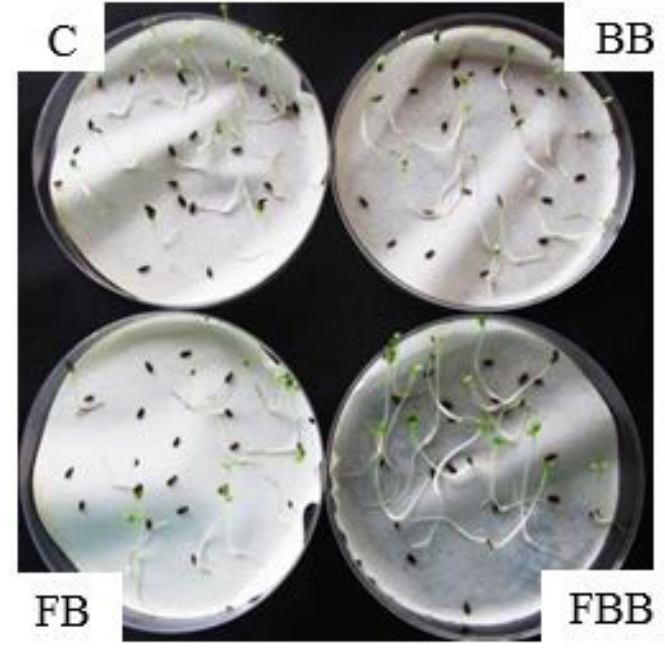

A

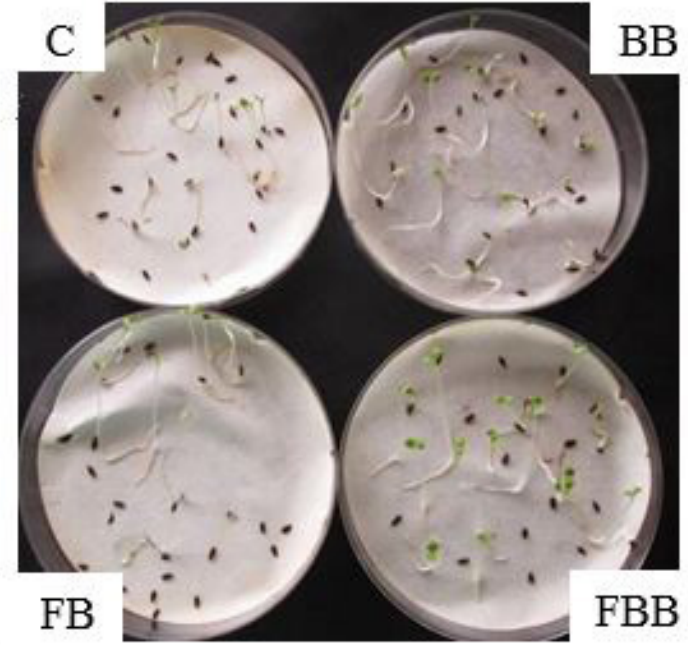

B

Figure 5: The lettuce seedlings A. treated with biofilm exudates collected at 0.5 day; B. treated with biofilm exudates collected at day 6 (C - Control, BB - Bacterial biofilm, FB - Fungal biofilm, FBB- Fungal-bacterial biofilm).

Table 1: Pearson correlation coefficient ( $r$ ) showing relationships of the seedling vigor and germination percentage of lettuce with functional polysaccharides, fatty acids and amides of the microbes.

\begin{tabular}{llll}
\hline Variables & Polysaccharides & Fatty acids & Amides \\
\hline \multirow{2}{*}{ Lettuce seedling vigor } & -0.54 & -0.15 & -0.37 \\
& $(0.000)$ & $(0.25)$ & $(0.000)$ \\
\hline \multirow{2}{*}{ Germination percentage } & -0.61 & -0.25 & -0.56 \\
& $(0.000)$ & $(0.05)$ & $(0.000)$ \\
\hline
\end{tabular}

*The probability levels are within parentheses.

* All data recorded at $0.25,0.5,1.5,3$ and 6 days were considered in the correlation analysis.

vigor (though not significantly) was observed in lettuce treated with 0.5 day old FBB exudates (Figure 4), while the least recorded with 6 days old $\mathrm{BB}, \mathrm{FB}, \mathrm{FBB}$ and 1.5 days old $\mathrm{BB}$ exudates. The mature biofilms showed the ability to accumulate the highest amount of functional polysaccharides and amides (Figures 1a, 1b). A negative correlation observed between the lettuce seedling vigor and functional polysaccharides and amides in the present study (Table 1) indicated that the accumulation of functional polysaccharides and amides may impose phytotoxic effect on lettuce seedlings, inhibiting their growth. The lettuce seeds treated by 0.5 day old $\mathrm{BB}$ and $\mathrm{FB}$ exudates also showed a reduced vigor over the control. This could be due to the phytotoxic effect caused by accumulated functional molecules in these two biofilms (Figure 1). Germination potential and seedling growth of lettuce seeds treated with 0.5 day and 6 days old FBB exudates demonstrated a healthy growth in comparison to others treated with $\mathrm{BB}$ and FB exudates (Figure 5).

The study confirms that BB, FB and FBB released functional polysaccharides, amides and fatty acids to their vicinity in varying concentrations. However, FBB released a somewhat different set of functional molecules (according to the cluster analysis given in Figure $2 a, b$ and c) in contrast to its monospecific counterparts. In all biofilms, functional molecules accumulate over time, potentially causing phytotoxic effects to plants. However, the exudates of FBB showed a potential to promote growth of lettuce seedlings over exudates of $\mathrm{BB}$ and $\mathrm{FB}$, further confirming their exclusive nature. Thus, the potential use of exudates of fresh FBB in plant growth promotion is highlighted in the present study. One important message conveyed from this study is that it is the type of biofilm, which is more crucial in developing biofertilizers for agriculture, but not the type of microbial species.

\section{ACKNOWLEDGEMENT}

The study was partially funded by University Grants Commission of Sri Lanka (UGC/ICD/RG/02/2012/10). We acknowledge Mr. Anura Pathirana, Chief Technical Officer of the National Institute of Fundamental Studies for his technical assistance.

\section{DECLARATION OF CONFLICT OF INTEREST}

The authors declare that there is no conflict of interest.

\section{REFERENCES}

Abdul-Baki, A.A. (1974). Pitfalls in using sodium hypochlorite as a seed disinfectant in ${ }^{14} \mathrm{C}$ incorporation studies. Plant Physiology 53(5): 768-771.

Allen, J., Davel, H.M., Broadhurst, D., Heald, J.K., Rowland, J.J., Oliver, S.G. and Kell, D.B. (2003). High-throughput classification of yeast mutants for functional genomics using metabolic foot printing,. 
Nature Biotechnology 21(6): 692-696.

Bandara, W.M.M.S., Seneviratne, G. and Kulasooriya, S.A. (2006). Interactions among endophytic bacteria and fungi: effects and potentials. Journal of Biosciences 31(5): 645-650.

Crouzet, M., Le Senechal, C., Brözel, V.S., Costaglioli, P., Barthe, C., Bonneu, M., Garbay, B. and Vilain, S. (2014). Exploring early steps in biofilm formation: setup of an experimental system for molecular studies. BMC Microbiology 14(1): 253.

Deveau, A., Barret, M., Diedhiou, A.G., Leveau, J., de Boer, W., Martin, F., Sarniguet, A. and Frey-Klett, F. (2015). Pairwise transcriptomic analysis of the interactions between the ectomycorrhizal fungus Laccaria bicolor S238N and three beneficial, neutral and antagonistic soil bacteria. Microbial Ecology 69(1): 146-159.

Flemming, H., Neu, T.R. and Wozniak, D.J. (2007). The EPS matrix: the "house of biofilm cells". Journal of Bacteriology 189(22): 7945-7947.

Garcia, D.E., Baidoo, E.E., Benke, P.I., Pingitore, F., Tang, Y.J., Villa, S. and Keasling, J.D. (2008). Separationand mass spectrometry in microbial metabolomics. Current Opinion in Microbiology 11(3): 233-239.

Haque, A.H.M.M., Akon, M.A.H., Islam, M.A., Khalequzzaman, K.M. and Ali, M.A. (2007). Study of seed health, germination and seedling vigor of farmers produce rice seeds. International Journal of Sustainable Crop Productivity 2(5): 34-39.

Herath, H.M.L.I., Senanayeke, D.M.N., Seneviratne. G. and Bandara, D.C. (2013). Variation of biochemical expressions of developed fungal-bacterial biofilms over their monocultures and its effect on plant growth. Tropical Agricultural Research 24: 186-192.

Jefferson, K.K. (2004). What drives bacteria to produce a biofilm? FEMS Microbiological Letters 236(2): 163173.

Jiao, Y., Cody, G.D., Harding, A.K., Wilmes, P., Schrenk, M., Wheeler, K.E., Banfield, J.F. and Thelen, M.P. (2010). Characterization of extracellular polymeric substances from acidophilic microbial biofilms. Applied and Environmental Microbiology 76(9): 2916-2922.

Madsen, J.S., Burmølle, M., Hansen, L.H. and Sørensen, S.J. (2012). The interconnection between biofilm formation and horizontal gene transfer. Immunology and Medical Microbiology 65(2): 183-195.

Mapelli, V., Olsson, L. and Nielsen, J. (2008). Metabolic foot printing in microbiology: methods and applications in functional genomics and biotechnology. Cell 26(9): 490-497.

Molin, S., Tolker-Nielsen, T., 2003, Gene transfer occurs with enhanced efficiency in biofilms and induces enhanes stabilization of the biofilm structure. Current Opinion in Biotechnology 14(3): 255-261.

O'Toole, G. and Kolter, R. (1998). Initiation of biofilm formation in Pseudomonas fluorescens WCS365 proceeds via multiple, convergent signaling pathways: a genetic analysis. Molecular Microbiology 28(3): 449461.

Sardans, J., Peñuelas, J. and Rivas-Ubach, A. (2011). Ecological metabolomics: overview of current developments and future challenges. Chemoecology
21(4):191-225.

Schroeckh, V., Scherlach, K., Nützmann, H., Shelest, E., Schmidt-Heck, W., Schuemann, J., Martine, K., Hertweck, C. and Brakhage, A.A. (2009). Intimate bacterial-fungal interaction triggers biosynthesis of archetypal polyketides in Aspergillus nidulans. PNAS 106 (34): 14558-14563.

Seneviratne, G. and Indrasena, I.K. (2006). Nitrogen fixation in lichens is important for improved rock weathering, Journal of Biosciences 31(5): 639-643.

Seneviratne, G. and Jayasinghearachchi, H.S. (2005). A rhizobial biofilm with nitrogenase activity alters nutrient availability in a soil, Soil Biology and Biochemistry 37(10): 1975-1978.

Singhalage, I.D., Seneviratne, G., Madawala, H.M.S.P. and Wijepala, P.C. (2019). Profitability of strawberry (Fragaria ananassa) production with biofilmed biofertilizer application, Scientia Horticulturae 243: 411-413.

Singhalage, I.D., Seneviratne, G., Madawala, H.M.S.P. and Manawasinghe, I.S. (2018). Characterization of structural properties of fungal-bacterial bioflms by Fourier Transform Infrared Spectroscopy. Ceylon Journal of Science 47(1): 77-83.

Soberón-Chávez, G., Lépine, F. and Déziel, E. (2005). Production of rhamnolipds by Pseudomonas aeruginosa, Applied Microbiology and Biotechnology 68(6): 718-725.

Sutherland, I.W., (2001) Biofilm exopolysaccharides: a strong and sticky framework, Microbiology 147(1): 3-9.

Wong, E.H.J., Ng, C.G., Goh, K.L., Vadivelu, J., Ho, B. and Loke, M.F., (2018). Metabolomic analysis of low and high bioflm-forming Helicobacter pylori strains. Scientific Reports 8(1): 1409.

Zavahir, J.S. and Seneviratne, G. (2007). Potential of developed biofilms in generating bioactive compounds. Research Journal of Microbiology 2(4): 397-401. 